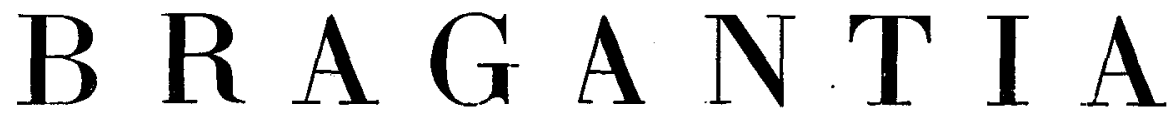

Boletim Científico do Instituto Agronômico do Estado de S. Paulo

Vol. 26

Campinas, junho de 1967

N. ${ }^{\circ} 18$

\title{
ABSORÇÃO DE NUTRIENTES POR PLANTAS DE AMENDOIM NA CULTURA DE OUTONO (1)
}

Fernando A. Soares Coelho, engenheiro-agrônomo, Seção de Fertilidade do Solo, e ROMEU DE TELLA, engenheiro-agrônomo, Seção de Oleaginosas, Instituto Agronômico

\section{SINOPSE}

É estudada a absorção e acumulação de elementos minerais e a acumulação de matéria sêca em plantas de amendoim, em diversas fases do ciclo vegetativo, em condições de campo.

Os resultados indicam maiores concentrações de nitrogênio e fósforo nas sementes, potássio nas hastes, cálcio na folhagem, magnésio nas hastes e fôlhas e enxôfre nas raízes. Os elementos extraídos em maiores quantidades foram: nitrogênio, potássio e cálcio.

Entre o inicio da floração e três semanas após o início da frutificação, foi absorvida a maior parte dos nutrientes. No tratamento com adubação, cêrca de $70 \%$ do total de elementos nutritivos foi absorvido nesse periodo. A acumulação de $74 \%$ e $48 \%$ do total de matéria sêca, respectivamente, para os tratamentos com e sem adubação, ocorreu nesse período, evidenciando a importância da disponibilidade de nutrientes às plantas, nessa fase.

\section{1 - INTRODUÇÃO}

O estudo das curvas de absorção dos elementos nutritivos pela planta através do ciclo vegetativo, fornece dados úteis sôbre as necessidades nutricionais, nos vários estádios do seu desenvolvimento, o que constitui a base para a solução dos problemas de fertilidade do solo para a cultura.

(1) Trabalho realizado com auxilio a Fundação de Amparo a Pesquisa do Estado đe São Paulo. Apresentado na XVII Reunião Anual da Sociedade Brasileira para o Progresso da Ciếncia, realizada em Belo Horizonte, Minas Gerais, de 4 a 10 de julho de 1965 . Recebido para publicação em 8 de fevereiro de 1967. 
Para iniciar êsse eștudo, nas condiçōes do planalto paulista, instalaram-se na Estação Experimental "Theodureto de Camargo", em Campinas, ensaios de adubação para o amendoim, com determinação da composição química das diferentes partes da planta, em várias fases do ciclo vegetativo.

No presente trabalho são relatados os resultados obtidos no ensaio instalado na cultura de outono, "amendoim da sêca", no ano agrícola de 1961/62.

\section{2 - MATERIAL E MÉTODO}

Em solo terra-roxa-misturada, foram plantados alguns, canteiros de amendoim sem adubo e com adubação completa. Os canteiros constaram de cinco linhas de 9 metros de comprimento, sendo três delas úteis e duas bordaduras, e o espaçamento de $60 \mathrm{~cm}$ entre linhas e $10 \mathrm{~cm}$ entre plantas. A variedade utilizada foi a Tatu, duas sementes por cova, ficando uma planta após o desbaste. Esta prática foi efetuada a fim de garantir um "stand" o mais uniforme possível.

A adubação utilizada inclui macro e micronutrientes, de acôrdo com os seguintes adubos e doses, em quilogramas por hectare: Salitre do Chile, 390 ; superfosfato simples, 600 ; cloreto cle potássio, 135; sulfato de cálcio, 500; sulfato de zinco, 20; sulfato de cobre, 20; borax, 3; molibdato de amônio, 0,115. $O$ Salitre do Chile, aplicado em cobertura, cêrca de 30 dias de idade da planta, e os demais na linha, por ocasiāo do plantio. cultura.

Os tratos culturais foram os mesmos preconizados para a

A análise química do solo $\left({ }^{2}\right)$ colhido antes dos tratamentos, revelou os seguintes resultados:

$$
\begin{aligned}
& \mathrm{pH} \ldots \ldots \ldots \ldots \ldots \ldots \ldots \ldots \ldots . \quad 5,15 \\
& \text { Nitrogênio ( } \mathrm{N} \text { ), g/100 g de solo .... } 0,12 \\
& \mathrm{Ca}++ \text { trocável, e.mg/100 g de solo .. } 0,30 \\
& \mathrm{Mg}++ \text { trocável, e.mg/100, } \mathrm{g} \text { de solo .. } 0,30 \\
& \mathrm{~K}+\text { trocável, e.mg/100 g de solo ... } 0,04 \\
& \mathrm{Al}+++ \text { trocável, e.mg/100 g de solo . . } 0,65 \\
& \mathrm{H}+\text { trocável, e.mg/100 } \mathrm{g} \text { de solo ... } 5,85 \\
& \mathrm{PO}_{+}^{--}\left({ }^{3}\right) \text {, e.mg/100 } \mathrm{g} \text { de solo ....... } 0,016
\end{aligned}
$$

\footnotetext{
(2) Análise efetuada na Seção de Fertilidade do Solo, dèste Instituto Agro-

(3) Fosfato solúvel em $\mathrm{H}_{.2} \mathrm{SO}_{4} 0.05 \mathrm{~N}$.
} 
FERNANDO A. SOARES COELHO \& ROMEU DE TELLA

Pelos dados da análise química do solo, verifica-se que, com exceção do teor de nitrogênio, que é médio, o solo apresenta teor baixo em todos os nutrientes e acidez média.

O amendoim foi semeado em 23 de janeiro de 1962 e colhido em 11 de maio. A distribuição das chuvas não foi inteiramente favorável ao desenvolvimento das plantas e formação dos frutos.

A amostragem foi feita arrancando-se com enxadão 20 plantas por vez, de cada tratamento. A primeira amostragem foi efetuada duas semanas após a germinação, e as demais, até a colheita, semanalmente.

Colhidas as amostras, estas foram levadas imediatamente ao laboratório, onde foi anotado o pêso verde total. Em seguida separaram-se as partes: raizes, hastes, fôlhas, frutos em casca e sementes.

As amostras foram lavadas, sêcas em estufa a $60-70^{\circ} \mathrm{C}$, os seus pesos secos anotados e moídas em moínho Wiley médio, com peneira de malha 20.

Uma vez preparadas, as amostras foram submetidas às determinaçōes para nitrogênio, fósforo, potássio, cálcio, magnésio e enxôfre, segundo métodos descritos por Lott e outros ( 9 e 10 ).

\section{3 - RESULTADOS OBTIDOS}

\section{1 - ACUMULAÇÃO DE MATÉRIA SÊCA}

Observando os dados de produção de matéria sêca pelas plantas de amendoim e de sua distribuição na planta (figura 1), nota-se que houve aumento de pêso da planta total e dos frutos a.té a época da colheita, em ambos os tratamentos. $\mathrm{Na}$ parte vegetativa êsse aumento se verificou até a nona semana de idade, nas plantas que receberam adubação, e até a oitava, no caso do tratamento sem adubação.

No estádio em que a parte vegetativa atingiu o pêșo máximo (plantas com 63 dias de idade), a adubação motivou um aumento de cêrca de $36 \%$ na matéria sêca, tanto dessa parte como das plantas. $O$ aumento de matéria sêca nas plantas de ambos os tratamentos intensificou-se a partir do início da floração ( 28 dias), não se constatando, até então, diferença apreciável no pêso sêco das plantas sem e com adubação. 


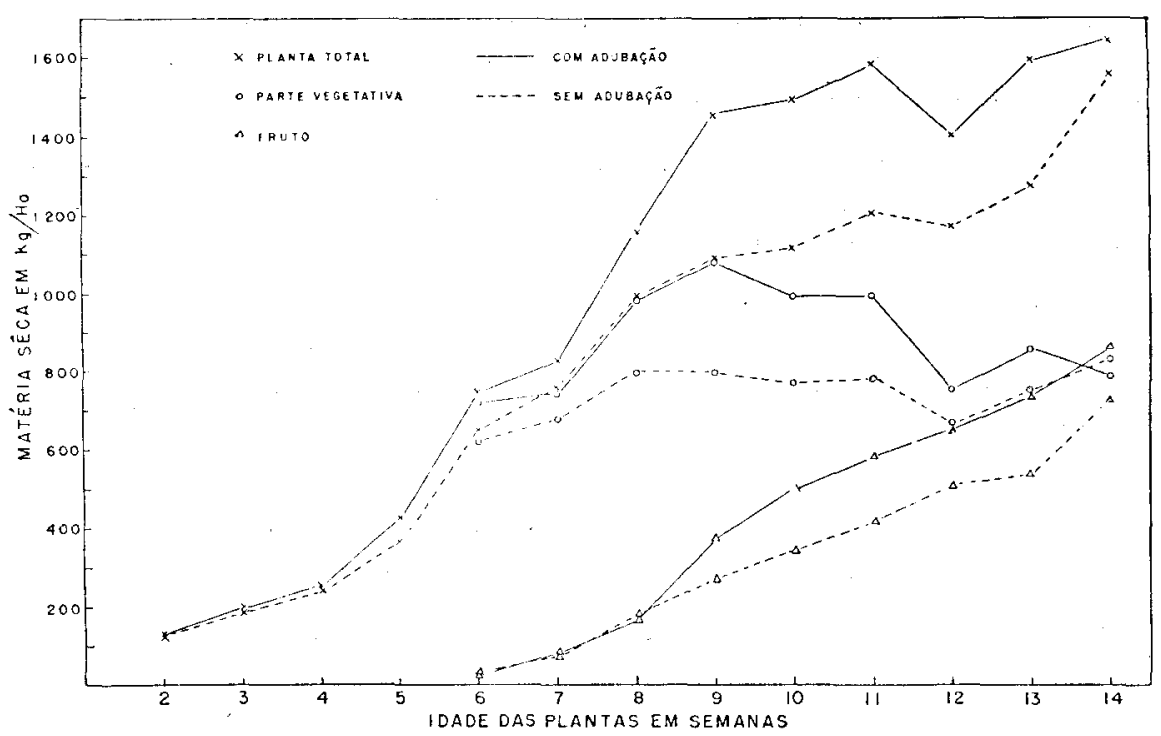

Figura 1. - Curvas de acumulação de matéria sêca pelas plantas de amendoim e partes da planta nos tratamentos sem e com adubação.

Aos 56 dias após a germinação o pêso sêeco da planta quadriplicou em relação ao do início da floração. A figura 1 mostra que no fim do ciclo vegetativo os frutos alcançaram um pêso sêco superior ao da parte vegetativa, nas plantas adubadas. O mesmo não se verificou nas não adubadas, o que deve estar relacionado à maior disponibilidade de nutrientes fornecidos pela adubação. Na época da colheita, os frutos representaram $46,8 \%$ e $52,3 \%$ do pêso sêco total, respectivamente, para os tratamentos sem e com adubação.

A redução no pêșo da parte vegetativa a partir da nona semana de idade pode ser explicada:

a) pela queda de fôlhas que se iniciou, aproximadamente, nessa época e foi intensificando até o fim do ciclo vegetativo, devido ao ataque da moléstia "mancha das fôlhas", causada pelo fungo Cercospora Sp.;

b) pela redistribuição da matéria sêca na planta.

Os dados de produção de frutos e massa verde, na colheita, podem ser observados no quadro 1 , indicando pouco efeito da adubação, possivelmente devido à falta de condições climáticas adequadas. 
FERNANDO A. SOARES COELHO \& ROMEU DE TELLA

QUADRo 1. - Produções, em quilogramas por hectare, de amendoim em casca e massa verde

\begin{tabular}{|c|c|c|}
\hline Tratamento & Amendoim em casca & Massa verde \\
\hline Solo não adubado & 782 & 5.243 \\
\hline solo adubado & 1.060 & 6.493 \\
\hline
\end{tabular}

\section{2 - VARIAÇÃO NA CONCENTRAÇÃO DOS ELEMENTOS NUTRITIVOS}

As figuras 2 a 4 mostram a composição química da planta e de suas, partes, nas diferentes fases do ciclo vegetativo.

$\mathrm{Na}$ parte vegetativa das plantas não adubadas, os teores de nitrogênio, fósforo e potássio aumentaram até próximo da floração, quando iniciou um período de intenso aumento de material sêco, resultando numa diluição na concentração dêsses nutrientes; com relação ao cálcio e enxôfre êsse aumento prolongou-se um pouco mais, enquanto que a concentração de magnésio, pràticamente, não se alterou durante o ciclo vegetativo da planta.

No que se refere às plantas adubadas, os teores de nitrogênio, potássio e enxôfre decresceram do início ao fim do ciclo, e os teores de fósforo, cálcio e magnésio aumentaram até o inicio da frutificação. Para o fósforo êsșe período de aumento foi mais prolongado.

Nos frutos, os teores de nitrogênio e fósforo sofreram um decréscimo inicial para, em seguida apresentarem um aumento gradativo até a colheita; os de potássio e enxôfre experimentaram uma redução até o fim do ciclo, enquanto que os de cálcio e magnésio, embora apresentassem pequenas variações, mantiveram-se quase constantes. Este comportamento dos elementos nutritivos foi idêntico em ambos os tratamentos.

As sementes apresentaram os teores, mais elevados de nitrogênio e fósforo e os mais baixos de potássio e cálcio.

De modo geral, a adubação motivou um aumento na concentração dos nutrientes nas plantas, com exceção do magnésio, cujos teores foram inferiores aos apresentados pelas plantas não adubadas. Os maiores acréscimos nas concentrações, proporcionados pela adubação, verificaram-se com o nitrogênio e enxôfre. 


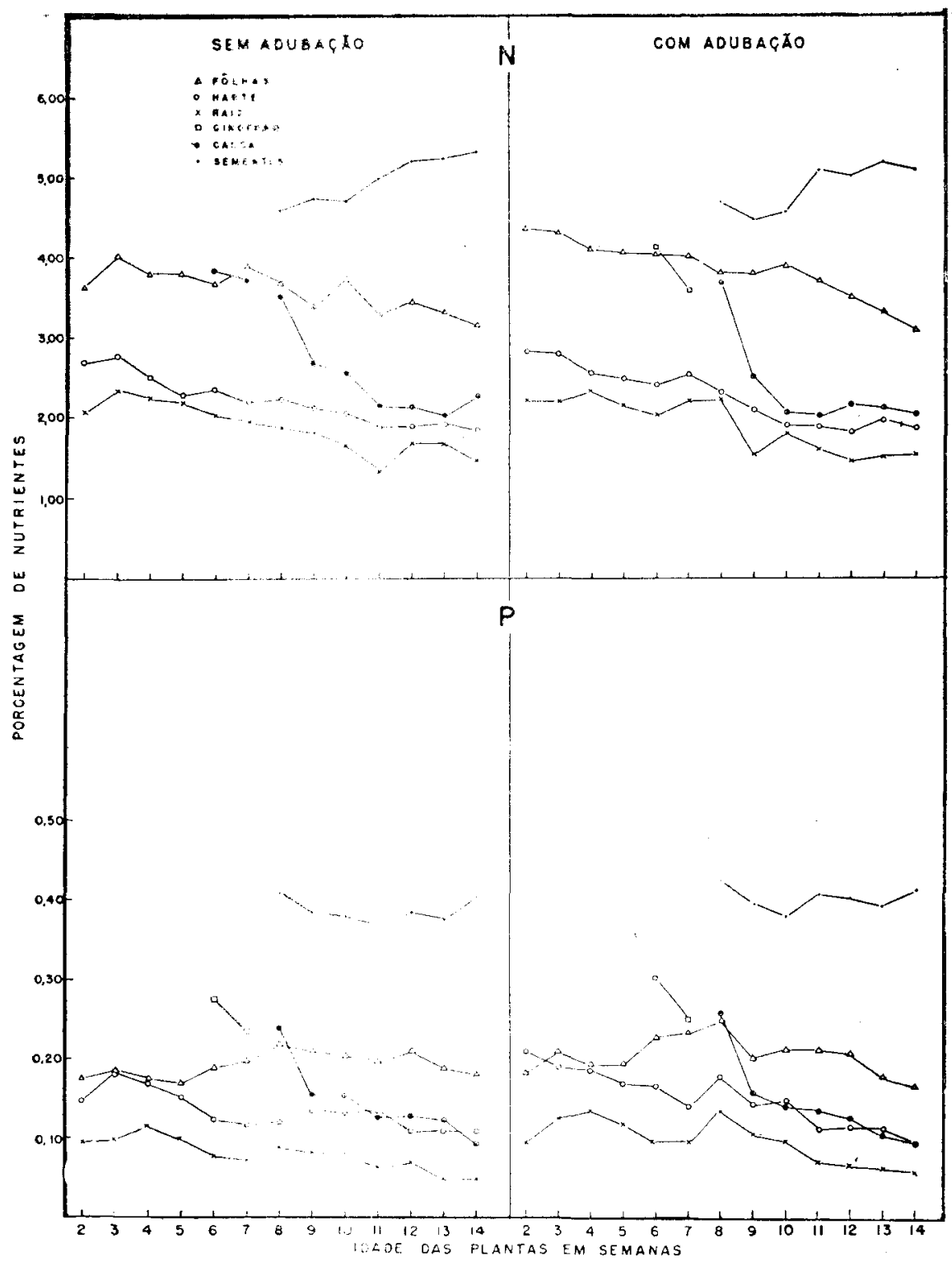

Figura 2. - Concentraçio de nitrogênio e fósforo nas diversas partes da planta

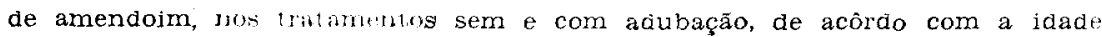
das plantas. 
FERNANDO A. SOARES COELHO \& ROMEU DE TELLA

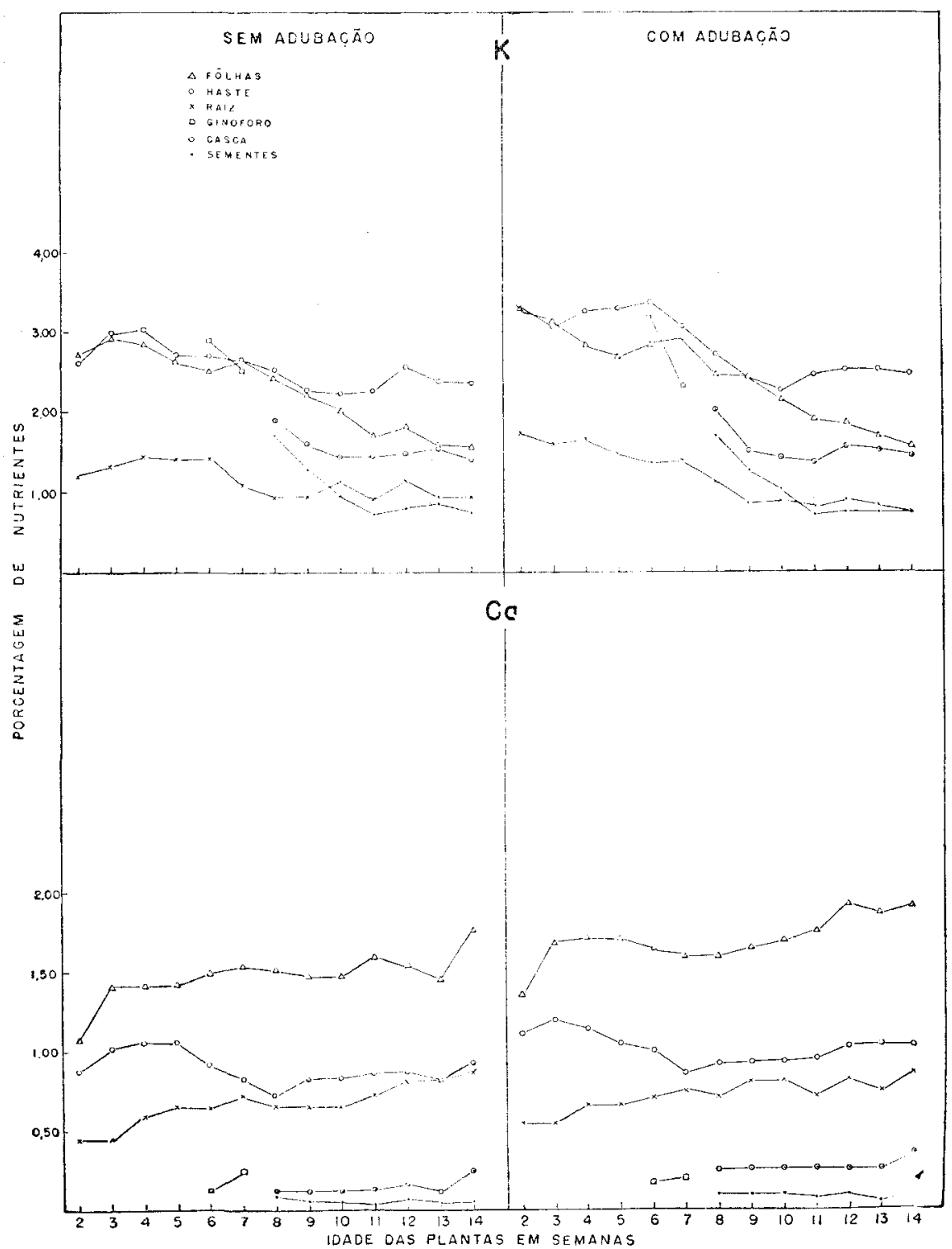

Figura 3. - Concentraçáo de potássio e cálcio nas diversas partes da planta de amendoim, nos tratamentos sem e com adubação, de acôrdo com a idade das plantas. 


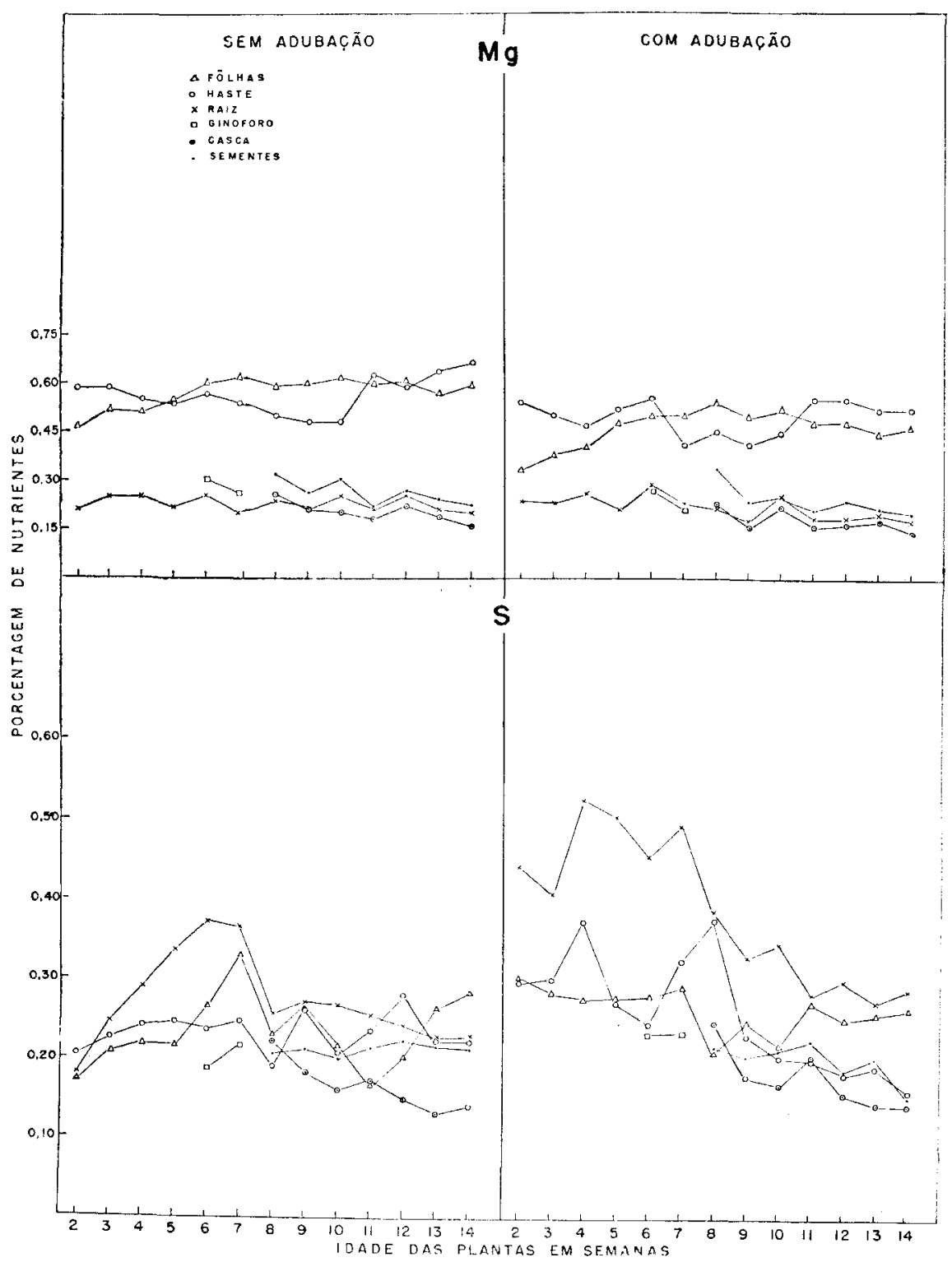

Figura 4. - Concentração de magnésio e enxôfre nas diversas partes da pianta de amendoim, nos tratamentós sem e com adubação. de acôrdo com a idade das piantas. 
FERNANDO A. SOARES COELHO \& ROMEU DE TELLA

\section{3 - ABSORÇÃO DE ELEMENTOS NUTRITIVOS}

\subsection{1 - QUANTIDADE E DISTRIBUIÇÃO}

As quantidades de nutrientes absorvidos pelas plantas e as suas distribuiçōes em partes da planta são apresentadas na figura 5 .

Os dados referentes às quantidades de elementos nutritivos extraídos pela planta total, menos fôlhas caídas, e pelos frutos, em quilogramas por hectare, nos tratamentos sem e com adubação, estão inseridos no quadro 2.

QUADRo 2. - Quantidades, em quilogramas por hectare, de elementos nutritivos extraídos pela planta total e pelos frutos

\begin{tabular}{|c|c|c|c|c|}
\hline \multirow{2}{*}{$\begin{array}{l}\text { Elementos } \\
\text { nutritivos }\end{array}$} & \multicolumn{2}{|c|}{ Planta total } & \multicolumn{2}{|c|}{ Fruto } \\
\hline & Sem adubo & Com adubo & Sem adubo & Com adubo \\
\hline Nitrogênio $\ldots \ldots$ & 49,33 & 52,65 & 30,72 & 34,54 \\
\hline Fósforo $\ldots \ldots \ldots \ldots \ldots \ldots$ & 3,22 & 3,50 & 2,14 & 2,57 \\
\hline Potássio & 23,94 & 24,00 & 7.15 & 8,48 \\
\hline Cálcio & 10,80 & 12,27 & 0,88 & 1,61 \\
\hline Magnésio $\ldots \ldots \ldots \ldots \ldots$ & 6,48 & 5,30 & 1,44 & 1.54 \\
\hline Enxôfre $\ldots \ldots \ldots$ & 3,34 & 2,93 & 1,35 & 1,29 \\
\hline
\end{tabular}

Os elementos absorvidos em maiores quantidades, em ordem clecrescente, foram nitrogênio, potássio e cálcio. A absorção dos demais, foi em quantidades pequenas.

É interessante salientar que cêrca de $62 \%$ e $66 \%$ do nitrogênio absorvido pelas plantas sem e com adubação, respectivamente, estão encerrados nos frutos $O$ mesmo se observou para o fósforo nos valores de $67 \%$ e $73 \%$.

Para os, demais nutrientes, as maiores quantidades são encontradas na parte vegetativa, sendo que para o cálcio, aproximadamente, $50 \%$ do total absorvido acha-se distribuído pelas 


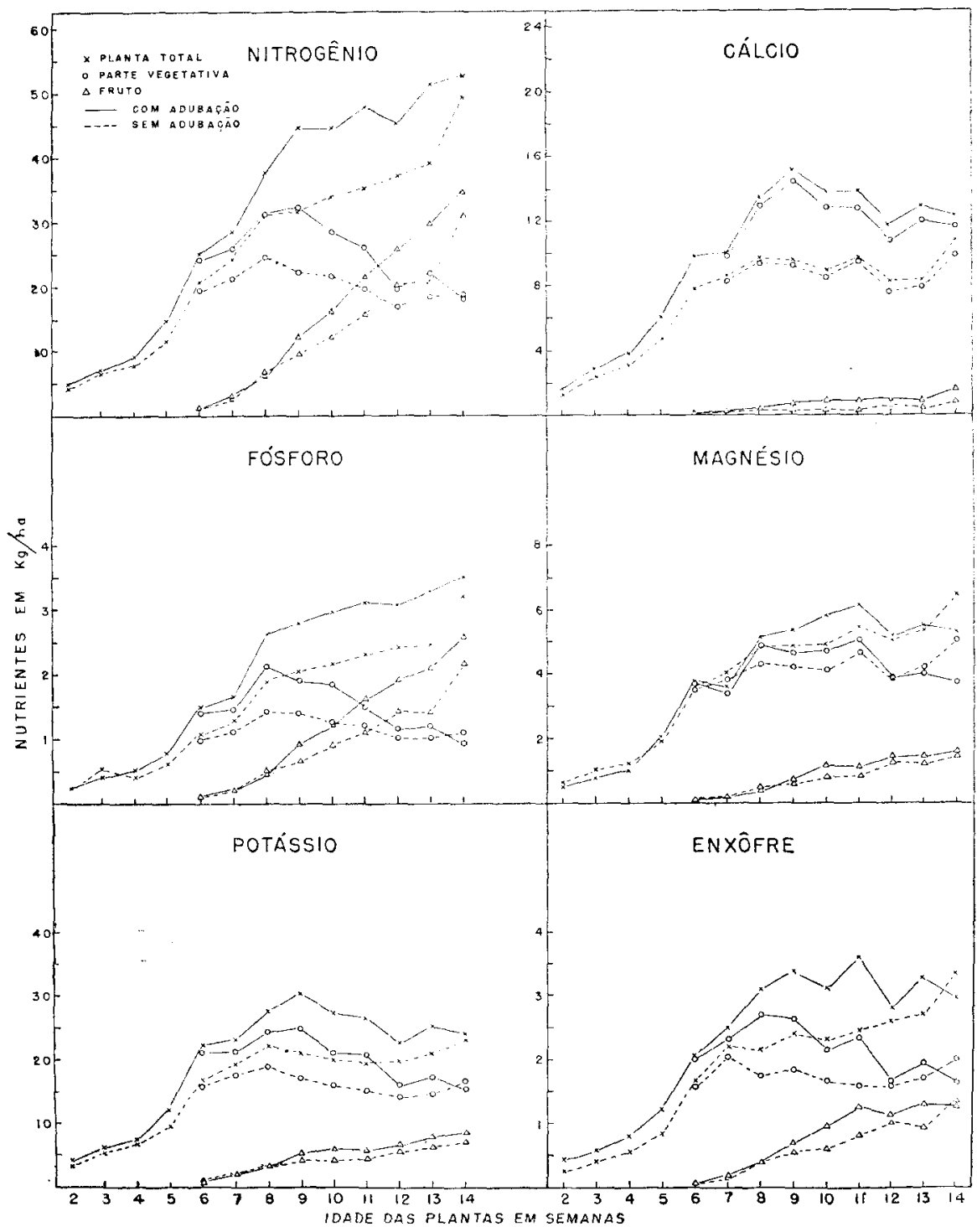

Figura 5. - Curvas de absorção de nutrientes, em $\mathbf{k g} / \mathbf{h a}$, pelas plantas de amendoim e distribuição em partes da planta, através do ciclo vegetativo. nos tratamentos sem e com adubação 
fôlhas; porcentagem idêntica de potássio e magnésio é encontrada nas hastes, e a maior quantidade de enxôfre é encontrada nos frutos, seguidos das hastes e fôlhas.

Como se observa na figura 5 , as quantidades totais de nutrientes absorvidos, com exceção do nitrogênio e fósforo, começam a decrescer a partir de certa fase do ciclo da planta, o que é explicado pela queda das fôlhas, que foi aumentando gradativamente até a colheita. Naturalmente, o mesmo não se constatou para os elementos citados, por se encontrarem em sua maior quantidade nos frutos.

A transmigração de nutrientes na planta foi observada, o que pode ser verificado pela comparação das figuras, que representam as concentrações e quantidades de nutrientes nas cascas e sementes através do desenvolvimento dos frutos, com exceção dos elementos pouco móveis na planta, como é o caso do cálcio.

A transmigração do nitrogênio e do fósforo da parte vegetativa para os frutos foi bem evidenciada.

Quanto à adubação ,nāo houve influência apreciável na quantidade absorvida dos nutrientes, possivelmente pela falta de condiçōeș adequadas de absorção.

A figura 5 revela um aumento gradativo nas quantidades de nutrientes nos frutos até a colheita. Para a parte vegetativa, essas quantidades decresceram a partir de certa fase de desenvolvimento das plantas até a época da colheita, com exceção do cálcio e magnésio nas plantas do tratamento sem adubação, que apresentaram um ligeiro aumento no fim do ciclo vegetativo.

Os dados mostram que a raiz encerra quantidades mínimas, dos totais de nutrientes extraídos pelas plantas.

\subsection{2 - INTENSIDA.DE DE ABSORÇÃO}

As atividades de absorçāo dos, diferentes nutrientes, em gramas num hectare por dia, em intervalo de amostragem até a época em que intensificou a queda das fôlhas, são apresentadas na. figura 6.

O periodo mais ativo de absorção de nutrientes, pelas plantas se verificou entre quatro e oito semanas de idade, correspondenco do inicio da floração ao inicio da formação da semente, isto é, quando foi possível a separaçāo do fruto em casca e semente. Nas plantas do tratamento adubado, êsse período se prolongou por mais uma semana. 


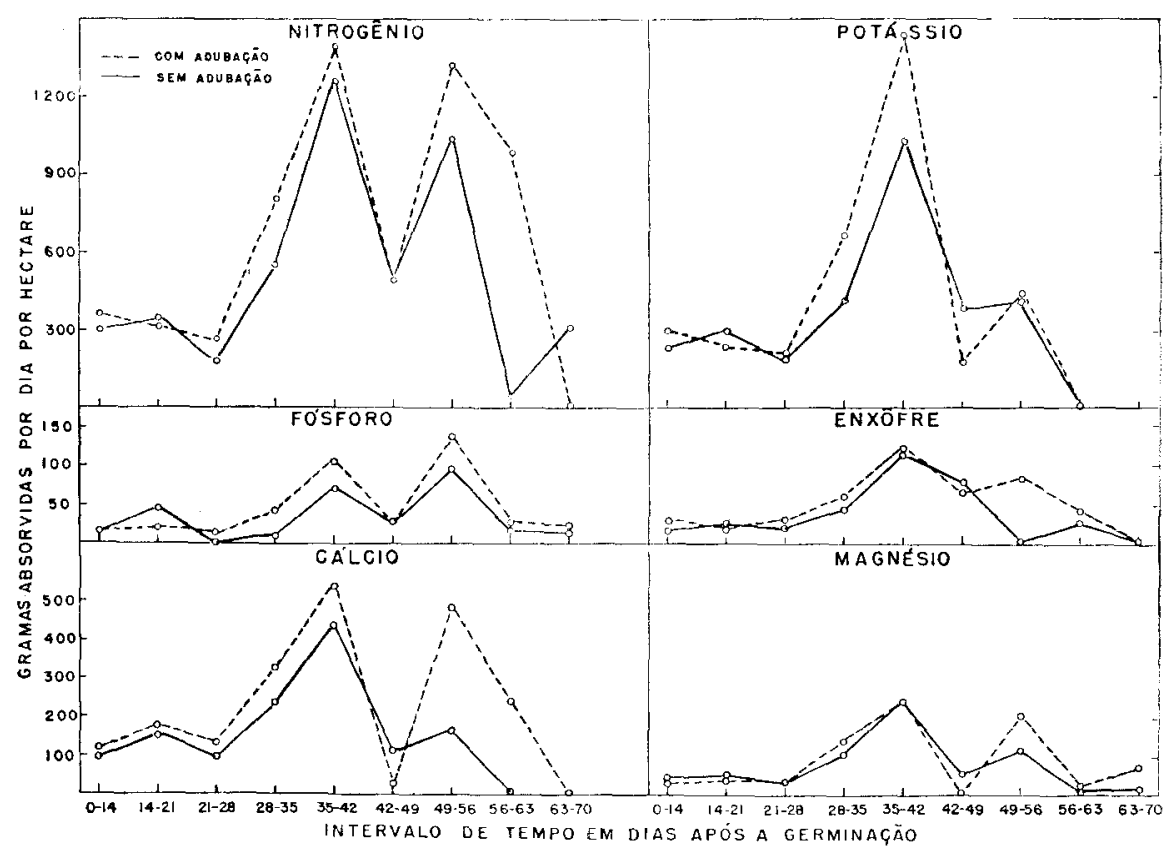

Figura 6. - Intensidade de absorção de nutrientes pelas plantas de amendoim. de acôrdo com o período de desenvolvimento, nos tratamentos sem adubaçãc e adubado.

O nitrogênio foi o elemento absorvido com maior intensidade; em seguida, por ordem decrescente, o potássio, cálcio, magnésio, enxôfre e fósforo.

A atividade máxima de absorção do fósforo ocorreu entre 49 e 56 dias apćs, a germinação; para os demais nutrientes entre 35 e 42 dias, em ambos os tratamentos. Neste período, houve uma acumulação de matéria sêca e nutrientes, respectivamente, para os tratamentos sem e com adubação, em gramas por hectare por dia: matéria șêca, 40.857 e 46.000 ; nitrogênio, 1.260 e 1.487 ; fósforo, 70 e 104 ; potássio, 1.031 e 1.438; cálcio 441 e 539; magnésio, 241 e 244; enxôfre, 114 e 119.

As porcentagens do total de matéria sêca e de cada nutriente, acumuladas nas plantas de amendoim por intervalo de amostragem, são apressentadas na figura 7 , a qual mostra essas porcentagens de acôrdo com o período de intensidade de acumulação. 
FERNANDO A. SOARES COELHO \& ROMEU DE TELLA
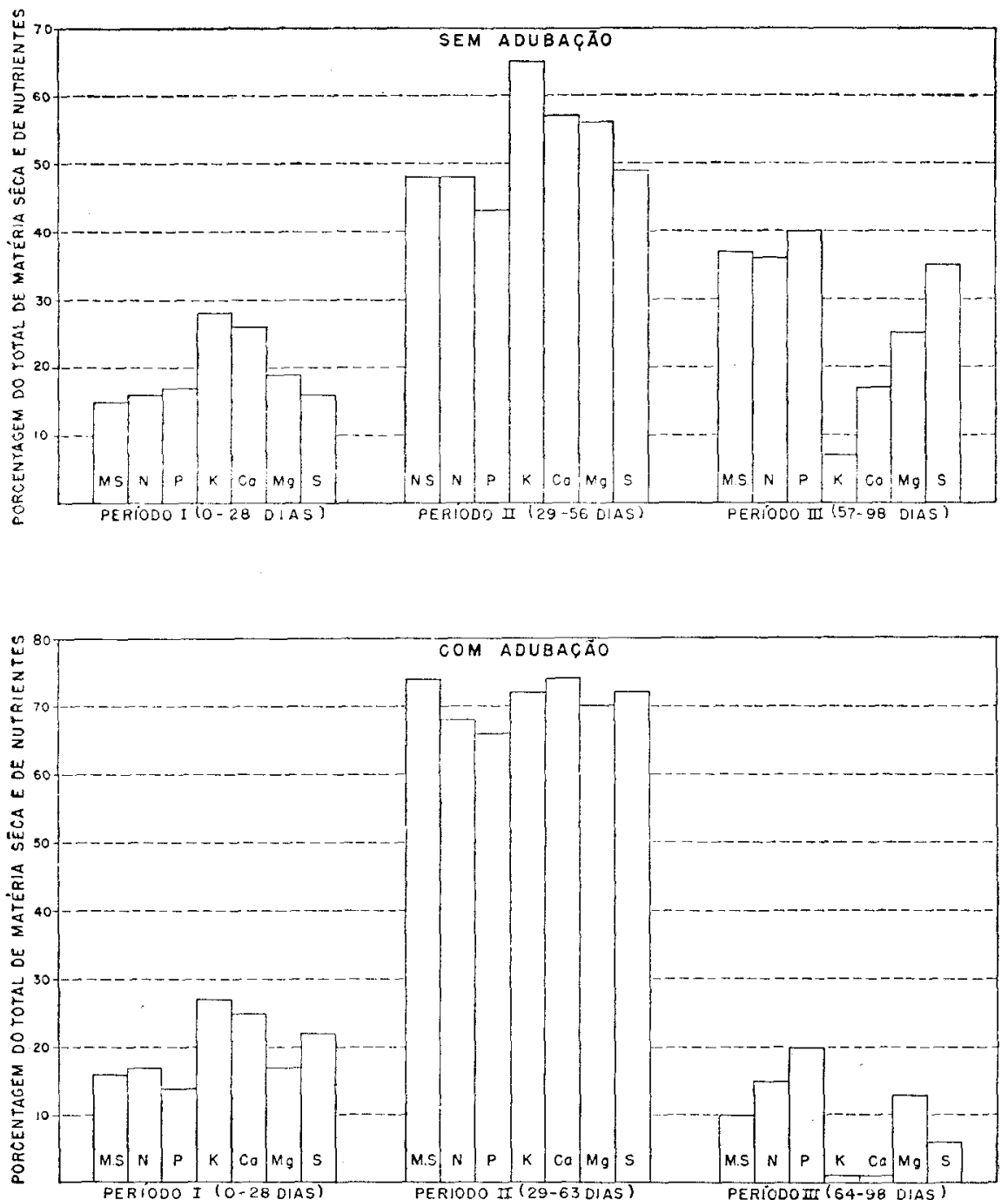

Figura 7. - Porcentagens do total de matéria sêca e nutrientes acumulados pelas plantas de amendoim, por periodo de desenvolvimento, em solo sem e com: adubação.

A análise dos dados revela que entre $43 \%$ e $65 \%$ do total de matéria sêca e de nutrientes foram acumulados no periodo de 29 a 56 dias de idade das plantas, no tratamento sem adubaçāo, e entre $66 \%$ e $74 \%$ no período de 29 a 63 dias para as plantas adubadas. 


\section{4 - DISCUSSÃO E CONCLUSÕES}

A acumulação de matéria sêca, durante as quatro primeiras semanas de idade das plantas, foi pequena, cêrca de $15 \%$ do total. A partir desta data, que coincide com o início da floração, a produção de material sêco intensificou-se até aos 56 dias após a germinação, para as plantas não adubadas, e 63 dias para as que receberam adubo. $O$ grande aumento de matéria sêca neste período está ligado ao desenvolvimento dos frutos, que à época da colheita compreenderam cêrca de $50 \%$ do pêso sêco total. Neste período de grande intensidade de produção de material sêco, verificou-se a acumulação de $48 \%$ e $74 \%$ do total produzido durante todo o ciclo vegetativo das plantas, respectivamente, para os tratamentos sem e com adubação.

A diferença nas porcentagens de acumulação, durante esta fase de desenvolvimento das plantas, provàvelmente deve estar ligada à maior disponibilidade de elementos nutritivos fornecidos pela adubação. As curvas de acumulação de matéria sêca pelas plantas de amendoim são semelhantes em ambos os tratamentos. A acumulação diária máxima se verificou, em ambos os tratamentos, entre 35 e 42 dias de idade das plantas.

Quanto às concentrações dos nutrientes nas plantas, os teores de nitrogênio, potássio e cálcio tendem a decrescer com a idade das plantas; o de fósforo a crescer, e os teores de magnésio e enxôfre aumentam até o início da frutificação, daí para frente decrescendo, enquanto que o teor de enxôfre nas adubadas decresce. As maiores concentraçōes de nitrogênio e fósforo, foram observadas nas, sementes; as de enxôfre nas raízes; de cálcio nas fôlhas; de potássio nas hastes; de magnésio nas hastes e fôlhas.

A absorção de nutrientes, até o início da floração, foi relativamente pequena. Neste estádio de desenvolvimento das plantas, o nitrogênio representa cêrca de $40 \%$ do total de nutrientes absorvidos, o potássio $34 \%$, o cálcio $16 \%$, e os outros $10 \%$ são representados pela absorção de fósforo, magnésio e enxôfre. À época da colheita estas porcentagens foram: para o nitrogênio, $51 \%$; para o potássio, $24 \%$; para o cálcio, $12 \%$; $15 \%$ para a soma de fósforo, magnésio e enxôfre. Os decréscimos nas porcentagens para o potássio e cálcio, devem estar relacionados com a transmigração de matéria sêca das hastes e fôlhas para os frutos, órgãos mais pobres nesses elementos. Também, a concentração de fósforo nos frutos é mais de duas 
vêzes a encontrada na parte vegetativa, o que pode explicar o acréscimo na porcentagem da soma de fósforo, magnésio e enxôfre.

De modo geral, a absorção máxima diária se verificou entre 35 e 42 dias de idade das plantas, coincidindo com o período de máxima acumulação diária de matéria sêca.

O período crítico, com relaçāo à nutrição das plantas de amendoim. verificou-se entre 29 e 56 dias para o tratamento não adubado e entre 29 e 63 dias para o adubado. Ėste período compreende o de absorção da maior parte do total de nutrientes extraídos pelas plantas em todo o seu ciclo vegetativo. No caso das plantas que receberam adubação, entre $66 \%$ e $74 \%$ da quantidade total foi absorvido neste período. Êstes dados vêm colocar em evidência a importância da disponibilidade de elementos nutritivos às plantas nesta fase do ciclo vegetativo, que vai do início da floração até três semanas após o aparecimento dos frutos.

Com relação aos efeitos da adubação, observou-se pouca influência sôbre a produção de material sêco total e de frutos. A adubação das plantas de amendoim motivou um aumento na concentração de todos os nutrientes estudados, com exceção do magnésio. Também, sôbre a quantidade de nutrientes extraída pelas plantas, pouca influência se observou, chegando a prejudicar a absorção do magnésio, posssivelmente pela ação antagônica entre êste elemento e o cálcio e potássio, já descrita por outros autores $(1,3$ e 4$)$.

Lachower e Feldhay ( 8 ) estudando a absorção de nitrogênio, fósforo e potássio pelas, plantas de amendoim, em diversos tipos de solos, mostraram que o início do período de grande atividade de acumulação de matéria sêca e absorção dêsses macronutrientes se verificou entre 30 e 60 dias, após a semeação e que grandes quantidades de nitrogênio e fósforo são absorvidas pelas plantas, sendo que a ordem de importância durante todo o ciclo vegetativo é a mesma: NPK. Verificaram, também, que os teores de nitrogênio e potássio decrescem com a idade das plantas.

Resultados semelhantes foram obtidos no presente trabalho, se considerarmos a absorção dêsses três macronutrientes.

Trabalhos realizados sôbre a extração e distribuição de nutrientes em plantas de amendoim (5, 4, 14) evidenciam que a maior parte do cálcio se encontra na folhagem das plantas e que o crescimento das raízes e produção de frutos são prejudicados pela deficiência de cálcio. Os resultados aqui obtidos sôbre a 
distribuição de cálcio nas plantas são concordantes, e observou-se que a quantidade de cálcio acumulada nos frutos das plantas adubadas foi o dôbro daquela encontrada nas plantas que não recebaram adubo.

Resultados obtidos em estudo de nutriçāo do amendoim (2,14) salientam as grandes quantidades de nitrogênio e fósforo contidas nas sementes em relação à planta tôda e que grande parte do nitrogênio é translocado das fôlhas, para o desenvolvimento dos frutos, o que coincide com os resultados do presente trabalho. Prevot (13), em estudo de nutrição mineral do amendoim, também coloca em evidência êsse resultado.

Em estudos de variação da composição de frutos de amendoim $(6,11,12)$ os dados indicam que a adubação afeta pouco a concentração dos nutrientes na semente, enquanto que o teor de cálcio na casca tem sido usada como índice de nutrição para o desenvolvimento dos frutos. Os dados sôbre a composição dos frutos que se obtiveram permitem consolidar as conclusōes dêsses pesquisadores, tendo-se encontrado que a concentração de cálcio na casca dos frutos das plantas que receberam adubação foi o dôbro daquela apresentada no tratamento sem adubação, a partir da amostragem em que foi possível a separação do fruto em semente e casca.

As quantidades de nutrientes extraidas pelas plantas de amendoim reveladas neste trabalho se aproximam daquelas obtidas por Bunking e Anderson (2) em trabalho realizado sôbre absorção de nutrientes, em Tanganyika, com exceção do nitrogênio, que foi extraído em quantidade superior à encontrada em nossa pesquisa.

Hammond e outros (7), realizando estudo semelhante com plantas de soja, apresentaram dados sôbre a composiçāo de frutos e plantas, cujas concentraçōes se aproximam das obtidas para zmendoim, com exceção dos teores de cálcio e magnésio, que nos frutos, de soja foram mais elevados.

\section{ABSORPTION OF NUTRIENTS BY PEANUT PLANTS}

\section{SUMMARY}

The absorption of nutrients and accumulation of substances in peanut plants at several growth stages were investigated. The studies were made on plants cultivated on "terra roxa misturada". The peanut variety Tatu 
FERNANDO A. SOARES COELHO \& ROMEU DE TELLA

was planted in non-fertilized plots and in others that received macro and micronutrients. Cultivation, spraying, and other cultural procedures were the same as those customary for commercial plantings.

Plant sampling started 15 days after emergence and was then carried out at intervals until harvest. For analytical purposes the samples were divided in root, stem, leaf, fruit shell, and seed.

The results obtained indicated the following pattern of nutrient accumulation in the plant: high concentrations of nitrogen and phosphorus in the seed; potassium and magnesium in the stem; calcium and rnagnesium in the foliage; and sulfur in the root. From the essential clements, nitrogen, potassium, and calcium were the most absorbed.

The highest nutrient demand occurred in the period between early blooming and three weeks after fruit initiation. In the fertilized plots $66 \%$ to $74 \%$ of all nutrients were absorbed by the peanut plant in this period. Also, $74 \%$ and $48 \%$ of the total dry matter were accumulated in the same period in plants from plots that received fertilizers and in those from non-fertilized plots, respectively. At harvest time, the fruits accounted for $50 \%$ of the total dry weight of the plant.

\section{LITERATURA CITADA}

1. BONNER, J. \& GALSTON, A. W. Principles of plant physiology. San Francisco, Freeman, $1952.499 \mathrm{p}$.

2. BUNKING, A. H. \& ANDERSON, E. Mineral nutrient uptake of Natal common groundnuts in Tanganyika. J. agric. Sci., 55: $35-46,1960$.

3. BURKHART, L. \& COLLINS, E. R. Mineral nutrients in peanut plant growth. Proc. Soil Sci. Omer., 6:277-280, 1962.

4. \& PAGE, N. R. Mineral nutrient extraction and distribuition in the peanut plant. J. Amer. Soc. Agron., 33: 743-755, 1941.

5. COLWELL, W. E. \& BRADY, N. C. The effect of calcium on yield and quality of large-seeded type peanut. J. Amer. Agron., $37: 413-428,1945$.

6.

\& PILAND. J. R. Composition of peanut shells of filled and unfilled fruits as affected by fertilizer treatments. J. Amer. Soc. Agron., 37:792-805, 1945.

7. HAMMOND, L. C.; BLACK, C. A. \& NORMAN, A. G. Nutrient uptake by soybeans on two Iowa soils. Ames. Iowa Agricultural Experiment Station, 1951. (Research bulletin 384)

8. LACHOVER, D. \& FELDHAY, H. Examen préliminaire de l'absorption de macro-éléments et du bilan fertilité du sol chez lea Arachides cultivées sous irrigation, en Israël. Oléagineux, $7: 599-611,1962$. 
9. LOTT, W. L.; McCLUNG, A. C. [e outros] Levantamento de cafèzais em São Paulo e Paraná pela análise foliar. São Paulo, IBEC Research Institute, 1961. 72p. (Boletim 26)

10. —_ _ _ _ [e outros] A técnica de análise foliar aplicada ao cafeeiro. Campinas, Instituto Agronômico, 1956. 29p. (Boletim 79)

11. MEHLICH, A. \& COLWELL, W. E. Absorption of calcium by peanuts from kaolin and bentonite at varying levels of calcium. Soil sci., 61:369-374, 1956.

12. — \& HEED, S. F. The influence of type of colloid and degree of calcium saturation on fruit characteristics of peanuts. Proc. Soil Sci. Soc. Amer., 11:201-205, 1947.

13. PREVOT, $P$. Nutrition minérale de l'arachide. Oléagineux, 4: 69-78, 1949.

14. YORK JR., E. T. \& COLWELL, W. E. The peanut: the unpredictable legume. 1951. 